\title{
Preparation and Field Emission Properties of Titanium Polysulfide Nanobelt Films
}

\author{
Xing Cai Wu $(\varangle)$, You Rong Tao, and Qi Xiu Gao \\ School of Chemistry and Chemical Engineering, and Key Laboratory of Mesoscopic Chemistry of Ministry of Education, Nanjing \\ University, Nanjing 210093, China \\ Received: 20 April 2009 / Revised: 9 May 2009 / Accepted: 10 May 2009 \\ (C) Tsinghua University Press and Springer-Verlag 2009. This article is published with open access at Springerlink.com
}

\begin{abstract}
$\mathrm{TiS}_{3}$ nanobelt films, with widths of about $0.1-12 \mu \mathrm{m}$, thickness of about 20-250 nm, and lengths of up to 200 $\mu \mathrm{m}$, have been grown on Ti substrates by a surface-assisted chemical-vapor-transport at $450{ }^{\circ} \mathrm{C}$ for $8 \mathrm{~h}$. $\mathrm{The} \mathrm{TiS}_{3}$ nanobelt films were converted into $\mathrm{TiS}_{1.71}$ nanobelt films by pyrolysis in a vacuum at $600{ }^{\circ} \mathrm{C}$ for $2 \mathrm{~h}$. The work functions of the two films were determined by ultraviolet photoelectron spectroscopy measurements to be 4.60 and $4.44 \mathrm{eV}$, respectively. Preliminary field emission experiments using the nanostructures as cold electron cathodes showed that both materials gave significant emission currents. The turn-on fields (defined as the electric field required to produce a current density of $10 \mu \mathrm{A} / \mathrm{cm}^{2}$ ) were about 1.0 and $0.9 \mathrm{~V} / \mu \mathrm{m}$, respectively, whereas the threshold fields (defined as the electric field required to produce a current density of $1 \mathrm{~mA} / \mathrm{cm}^{2}$ ) were about 5.6 and $4.0 \mathrm{~V} / \mu \mathrm{m}$, respectively. These data reveal that both materials have potential applications in field emission devices.
\end{abstract}

\section{KEYWORDS}

Nanowire, film, titanium sulfide, chemical vapor-transport, field emission

\section{Introduction}

One-dimensional (1-D) nanomaterials have attracted considerable interest due to their unique physical properties and potential applications in the construction of nanoscale electric and optoelectronic devices [1-6]. A few 1-D nanomaterials have already been synthesized and fabricated into devices [7-10], but for future rational development and optimization of functional devices it is important to synthesize novel 1-D nanostructures and to understand their fundamental physical properties.
Titanium trisulfide $\left(\mathrm{TiS}_{3}\right)$ is an n-type extrinsic semiconductor with good conductivity. It has a pseudo one-dimensional structure with infinite chains of triangular prisms $\left(\mathrm{TiS}_{6}\right.$ ) that share trigonal faces along the $b$-axis. Each chain is shifted with respect to two neighboring ones by half the lattice parameter along the $b$ direction [11]. Titanium disulfide $\left(\mathrm{TiS}_{2}\right.$ ) exhibits either semimetallic [12] or semiconducting [13] behavior due to a strong tendency toward nonstoichiometry with excess Ti. Over the past few years, $\mathrm{TiS}_{3}$ and $\mathrm{TiS}_{2}$ thin films have been prepared by chemical vapor deposition (CVD) of $\mathrm{TiCl}_{4}$ and a series

Address correspondence to wuxingca@netra.nju.edu.cn 
of sulfur sources [14], and $\mathrm{TiS}_{3}$ nanobelts have been prepared by a chemical vapor transport (CVT) of Ti sponge and $S$ powder [15]. In addition, $\mathrm{TiS}_{2}$ nanotubes have been prepared by the thermal decomposition of $\mathrm{TiS}_{3}$ in $\mathrm{H}_{2}$ at $800-1000{ }^{\circ} \mathrm{C}$ [16], and by heating $\mathrm{TiS}_{2}$ amorphous particles in $\mathrm{H}_{2}$ at $200{ }^{\circ} \mathrm{C}$ [17]. If 1-D nanostructures of $\mathrm{TiS}_{3}$ or $\mathrm{TiS}_{2}$ are fabricated on metal or semiconducting substrates, they can form electronic field emission (FE) functional blocks due to the strong local electric field at the tip and unique direction of electron emission. Earlier, Zhang et al. prepared $\mathrm{TiS}_{2}$ whisker arrays on Si substrates by a vapor deposition method, but no physical properties were studied [18]. We also fabricated $\mathrm{TiS}_{2}$ microplates on Ti substrates by surface-assisted CVT [19], but did not obtain any 1-D nanostructures. Here we report that by altering the previous experimental conditions, it is possible to obtain $\mathrm{TiS}_{3}$ nanobelt films on Ti foils, and that the $\mathrm{TiS}_{3}$ nanobelt films can be pyrolyzed in a vacuum to afford $\mathrm{TiS}_{1.71}$ nanobelt films. We also report FE measurements with both films.

\section{Experimental}

Titanium (Ti) foil (99.9\%) and sulfur (S) powder (99.8\%) were used as starting materials. Three pieces of Ti foil with size of ca. $0.2 \mathrm{~mm} \times 5 \mathrm{~mm} \times 11 \mathrm{~mm}$ (total weight: $136.0 \mathrm{mg})$ and S powder $(10.0 \mathrm{mg})$ were sealed in a quartz ampule $(\Phi 6 \mathrm{~mm} \times 130 \mathrm{~mm})$ under a vacuum (ca. $10^{-2} \mathrm{~Pa}$ ). The ampule was placed in a conventional horizontal furnace with a temperature gradient of ca. $10 \mathrm{~K} / \mathrm{cm}$ from center to edge. The end containing the Ti foil was put at the center of the furnace, and the ampule then heated at different temperatures $\left(350,450,550\right.$, and $\left.650^{\circ} \mathrm{C}\right)$ for $8 \mathrm{~h}$; finally $\mathrm{TiS}_{3}$ nanobelt arrays grown on Ti foil were obtained. After the furnace was cooled to room temperature, the pieces of foil with attached $\mathrm{TiS}_{3}$ nanostructures were extracted from the quartz ampule. The product obtained at $450{ }^{\circ} \mathrm{C}$ was sealed in a quartz ampule $(\Phi 6 \mathrm{~mm} \times 250 \mathrm{~mm})$ under a vacuum $\left(\mathrm{ca} .10^{-2} \mathrm{~Pa}\right)$. The end of the ampule containing the $\mathrm{TiS}_{3}$ nanostructure was put at the center of the furnace, with the other end extending out of the furnace by about $7 \mathrm{~cm}$, and the ampule was then annealed at $600{ }^{\circ} \mathrm{C}$ for $2 \mathrm{~h}$ in a vacuum so as to obtain $\mathrm{TiS}_{1.71}$ nanobelt films.
The products were characterized using an X-ray diffractometer (XRD; Shimadzu XRD-6000) with graphite monochromatized $\mathrm{Cu} \mathrm{K} \alpha$-radiation, a scanning electron microscope (SEM; LEO-1530VP) with attached energy-dispersive $\mathrm{X}$-ray spectrometer (EDX), and a high-resolution transmission electron microscope with a point resolution of $0.19 \mathrm{~nm}$ (HRTEM; JEOL model JEM-2100). The composition of the products was confirmed by a gravimetric method: the products scraped from the Ti foils were weighed, and converted to $\mathrm{TiO}_{2}$ by heating in air at $800{ }^{\circ} \mathrm{C}$ for $1 \mathrm{~h}$, and then cooled to room temperature. The atomic ratios of $\mathrm{Ti}$ and $\mathrm{S}$ were calculated based on the weight loss of the products. The work functions were measured by ultraviolet photoelectron spectroscopy (UPS, ESCALAB 250) with an ultraviolet excitation source (He I discharge at $h v=21.22 \mathrm{eV}$ ) in a vacuum of $3 \times 10^{-8} \mathrm{~Pa}$. The spectrum was recorded with a sample bias of $-3.500 \mathrm{~V}$ so that the sample inelastic cutoff could be distinguished from that of the spectrometer. The electron field emission measurements were performed by using a parallelplate configuration with a space of $500 \mu \mathrm{m}$ and an emission area of $0.41 \mathrm{~cm}^{2}$ in a vacuum chamber at a pressure of $5.0 \times 10^{-4} \mathrm{~Pa}$ at room temperature. A DC voltage sweeping from 0 to $4500 \mathrm{~V}$ was applied to the samples.

\section{Results and discussion}

\subsection{Structure and morphology}

Figures 1(a)-(d) show the XRD patterns of the films prepared by reaction of $\mathrm{Ti}$ foil with $\mathrm{S}$ at different temperatures. Figure 1(a) indicates the reflection peaks of the product obtained at $350{ }^{\circ} \mathrm{C}$, which can be indexed as the hexagonal phase of Ti (ICCD PDF no. 05-0682), revealing that $\mathrm{Ti}$ does not react with $\mathrm{S}$ below $350{ }^{\circ} \mathrm{C}$. Figures $1(\mathrm{~b})$ and $1(\mathrm{c})$ exhibit the reflection peaks of the nanostructures prepared at 450 and $550{ }^{\circ} \mathrm{C}$, respectively, which can be indexed as the monoclinic phase of $\mathrm{TiS}_{3}$ (ICCD PDF no. 36-1337; S. G.: $\left.\mathrm{P} 2{ }_{1} / \mathrm{m}\right)$. Figure $1(\mathrm{~d})$ displays the reflection peaks of the product obtained at $650{ }^{\circ} \mathrm{C}$, which can be indexed as the hexagonal phase of $\mathrm{TiS}_{2}$ (ICCD PDF no. 15-0853). After the films prepared at $450{ }^{\circ} \mathrm{C}$ were 
annealed in a vacuum at $600{ }^{\circ} \mathrm{C}$ for $2 \mathrm{~h}$, they were converted to hexagonal $\mathrm{TiS}_{1.71}$, for which the XRD pattern is shown in Fig. 1(e) (ICCD PDF no. 71-0374; S. G.: R $\overline{3} \mathrm{~m})$.

Figures 2(a)-(c) are SEM images of the $\mathrm{TiS}_{3}$ nanobelt films obtained at $450{ }^{\circ} \mathrm{C}$, which show that the nanobelts, with widths of about $0.1-12 \mu \mathrm{m}$, thickness of about $20-250 \mathrm{~nm}$, and lengths of up to $200 \mu \mathrm{m}$, were vertically or obliquely grown on the Ti substrate. The EDX spectrum (Fig. 2(d)) gave a the molar ratio of $\mathrm{Ti}$ to $\mathrm{S}$ of 24.2:75.8 (1:3.13), which is close to the expected stoichiometric composition. In addition, gravimetric analysis gave almost the same Ti/S molar ratio,1:3.10. Figures 2(e)-(g) show a high-magnification TEM image, a selected area electron diffraction (SAED) pattern, and an HRTEM image of a single $\mathrm{TiS}_{3}$ nanobelt, respectively. The SAED pattern can be indexed as $\mathrm{TiS}_{3}$ (ICCD PDF no. 36-1337), consistent with the above XRD results. Lattice fringe spaces of 0.49 and $0.34 \mathrm{~nm}$ correspond to (100) and (010) planes of $\mathrm{TiS}_{3}$, which demonstrate that the nanobelt grows along the [010] direction. The structure of the nanobelt is drawn as an inset in Fig. 2(g).

Figures 3(a)-(c) are SEM images of the nanobelt films obtained at $550{ }^{\circ} \mathrm{C}$, showing that the nanobelts, with widths of about $0.4-17 \mu \mathrm{m}$, thickness of about 50-300 nm, and lengths of up to $440 \mu \mathrm{m}$, grew almost vertically on the Ti substrate. EDX and XRD analyses demonstrate that the material is also $\mathrm{TiS}_{3}$ (ICCD PDF no. 36-1337). When the reaction was carried out at $650{ }^{\circ} \mathrm{C}$, only $\mathrm{TiS}_{2}$ particle films were formed as shown in Fig. 3(d).

Figures $4(\mathrm{a})-(\mathrm{c})$ are the SEM images of $\mathrm{TiS}_{1.71}$ nanobelt films with sizes and morphologies which approach those of the $\mathrm{TiS}_{3}$ nanobelt precursors prepared at $450{ }^{\circ} \mathrm{C}$. The EDX spectrum (Fig. 4(d)) confirms that the nanobelt is composed of Ti and $\mathrm{S}$ with a molar ratio of 36.95:63.05 (1:1.71). Gravimetric analysis shows that $\mathrm{Ti} / \mathrm{S}$ molar ratio of the products is $1: 1.76$, consistent with the EDX analysis. Figure 4(e) shows a TEM image and corresponding SAED pattern (inset) of a single $\mathrm{TiS}_{1.71}$ nanobelt. The SAED analysis supports the above XRD results and confirms that the nanobelt grows along the [100]

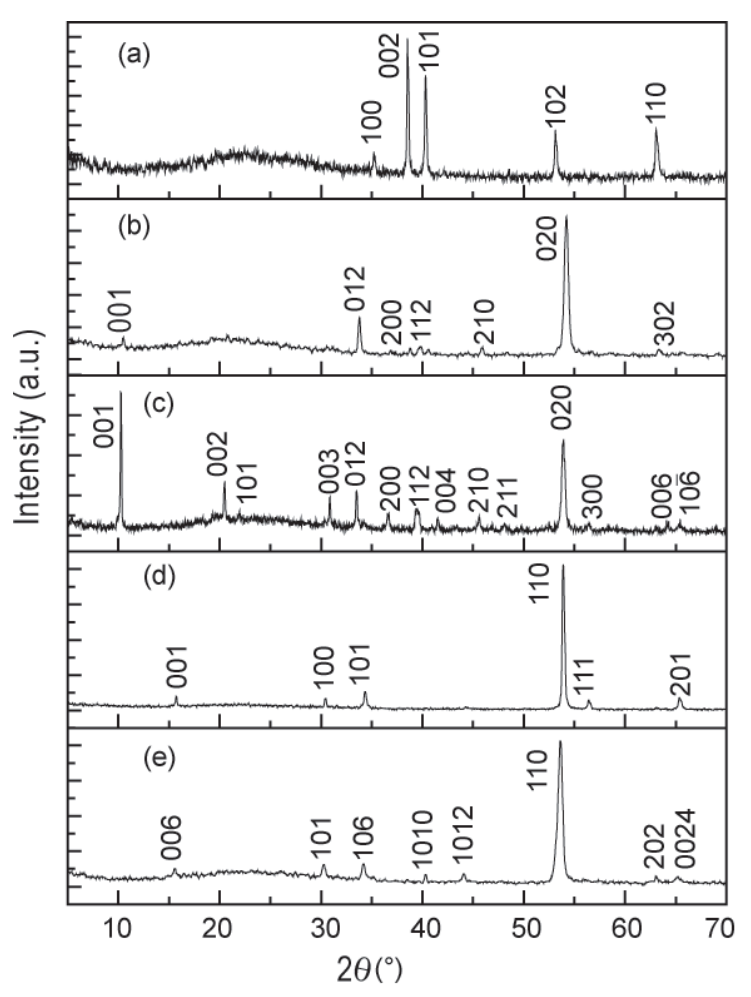

Figure 1 XRD patterns of the films prepared at (a) 350, (b) 450, (c) 550, and (d) $650^{\circ} \mathrm{C}$, and (e) $\mathrm{TiS}_{1.71}$ nanobelt film formed by pyrolysis of a $\mathrm{TiS}_{3}$ nanobelt film (prepared at $450{ }^{\circ} \mathrm{C}$ ) in vacuum at $600^{\circ} \mathrm{C}$
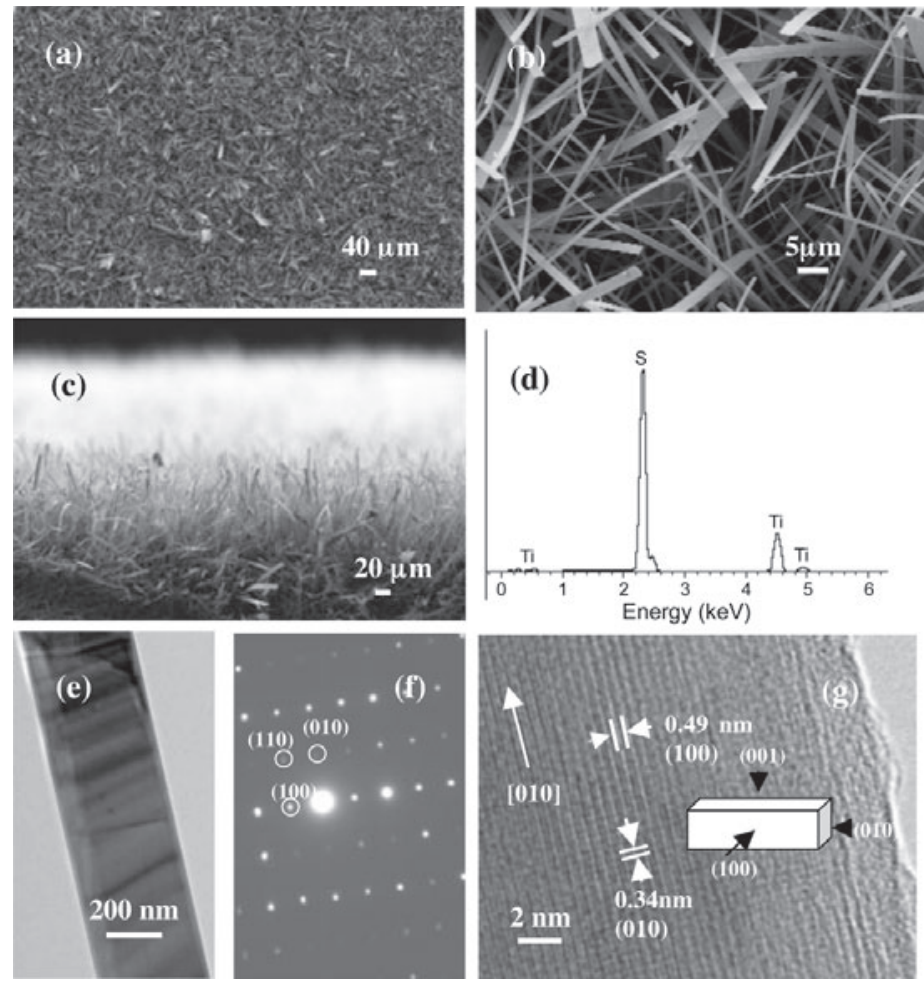

Figure 2 (a) Low-magnification plan-view; (b) high-magnification planview; (c) low-magnification side-view SEM images of a $\mathrm{TiS}_{3}$ nanobelt film prepared at $450{ }^{\circ} \mathrm{C}$; (d) EDX spectrum of $\mathrm{TiS}_{3}$ nanobelts. (e) TEM image; (f) SAED pattern; (g) HRTEM image of a single $\mathrm{TiS}_{3}$ nanobelt 

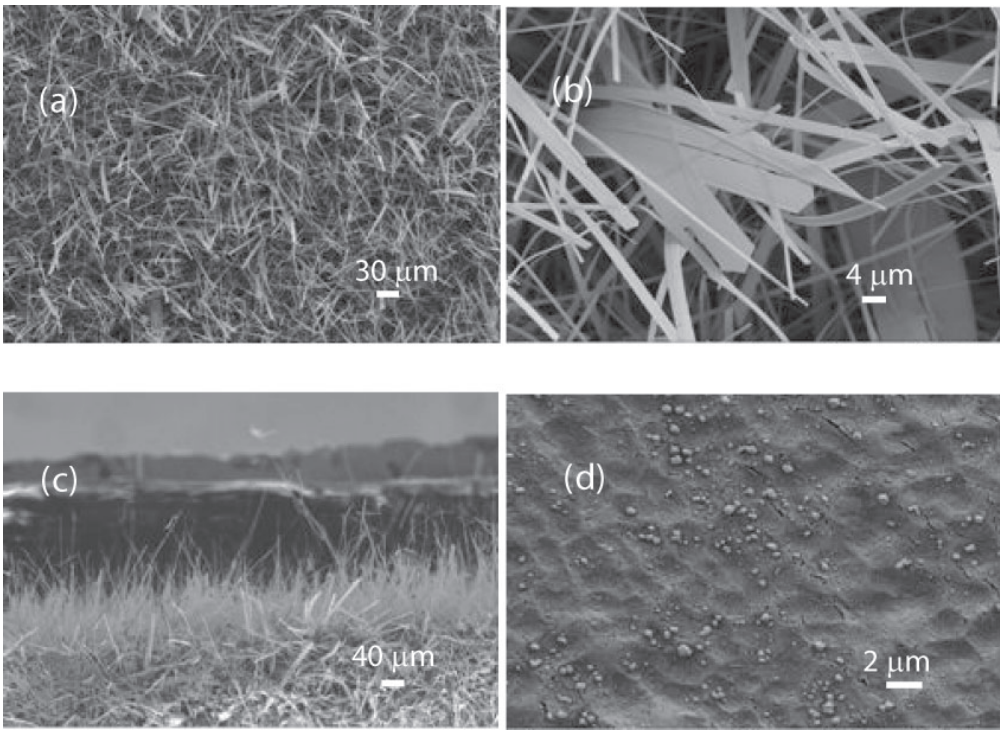

Figure 3 (a) Low-magnification plan-view; (b) high-magnification plan-view; (c) low-magnification side-view SEM images of a $\mathrm{TiS}_{3}$ nanobelt film prepared at $550^{\circ} \mathrm{C}$; (d) plan-view SEM image of a $\mathrm{TiS}_{2}$ particle film prepared at $650^{\circ} \mathrm{C}$
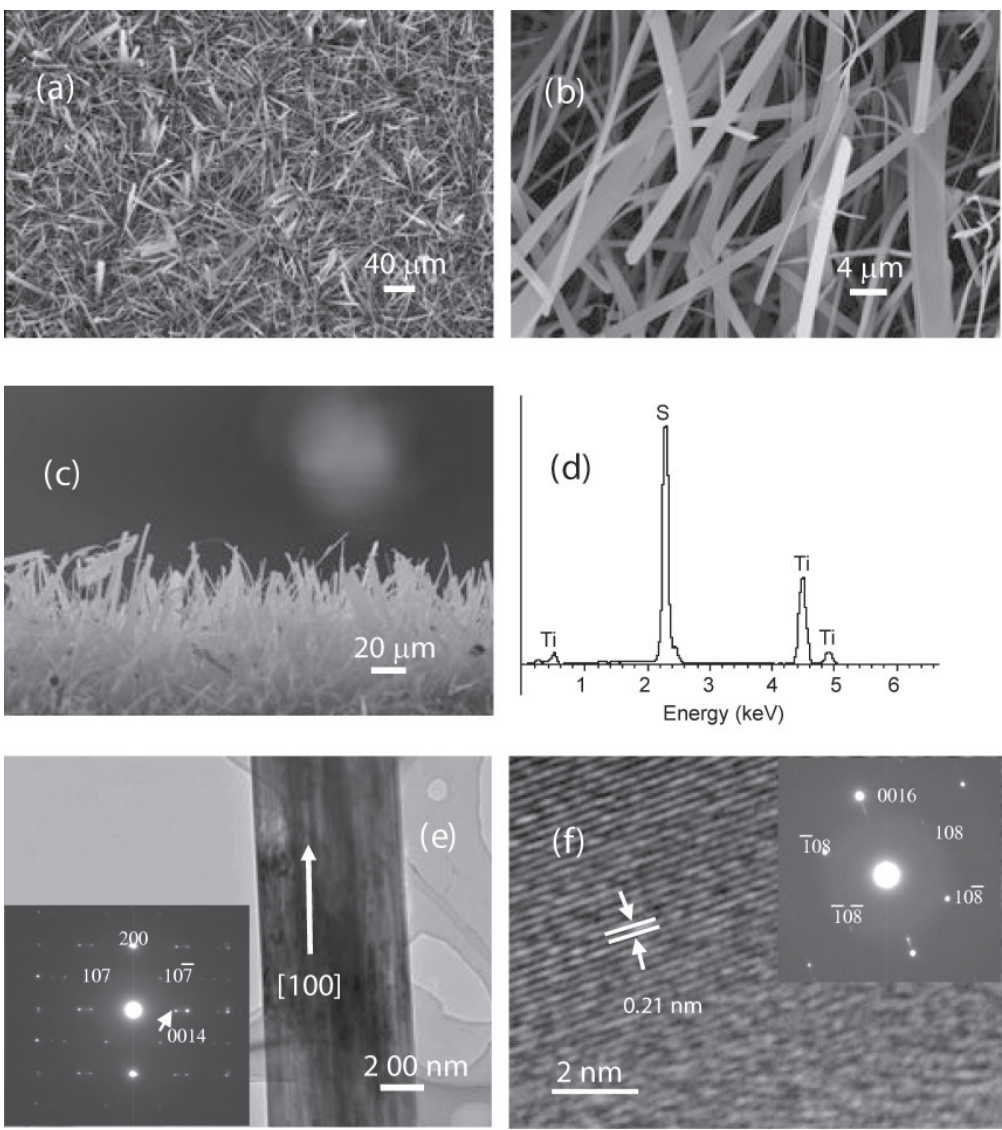

Figure 4 (a) Low-magnification plan-view; (b) high-magnification plan-view; (c) low-magnification side-view SEM images of a $\mathrm{TiS}_{1.71}$ nanobelt film prepared by vacuum pyrolysis of a $\mathrm{TiS}_{3}$ nanobelt film (obtained at $450{ }^{\circ} \mathrm{C}$ ); (d) EDX spectrum of TiS $_{1.71}$ nanobelts; (e) TEM image and corresponding SAED pattern (inset) of a single TiS $_{1.71}$ nanobelt; (f) HRTEM image and corresponding SAED pattern (inset) of a single $\mathrm{TiS}_{1.71}$ nanobelt direction. Figure 4(f) shows an HRTEM image and SAED pattern (inset) of a single $\mathrm{TiS}_{1.71}$ nanobelt. The lattice fringe space of $0.21 \mathrm{~nm}$ corresponds to the (0016) plane of $\mathrm{TiS}_{1.71}$.

\subsection{Growth mechanism}

Tips of nanobelts can be observed in Fig. 3(b) which suggests that the formation of $\mathrm{TiS}_{3}$ nanobelts can be explained by the vapor-solid growth mechanism [20]. When the reaction temperature reaches $450{ }^{\circ} \mathrm{C}$, sulfur (b.p. $444.6{ }^{\circ} \mathrm{C}$ ) is evaporated into the vapor phase, and deposits on the Ti substrate. Titanium reacts with sulfur vapor and forms unstable $\mathrm{TiS}_{x}$ species in the gas phase. $\mathrm{TiS}_{x}$ in the vapor phase reacts with further $S$ vapor, and condenses again on the Ti substrate to form stable $\mathrm{TiS}_{3}$ seeds. In the subsequent process, $\mathrm{TiS}_{x}$ and $S$ in the vapor phase may combine with $\mathrm{TiS}_{3}$ seeds to form $\mathrm{TiS}_{3}$ nanobelts. Owing to the presence of the seeds, $\mathrm{TiS}_{3}$ nanobelts stand almost vertically on the surface of the substrates, similar to the growth of $\mathrm{MoO}_{2}$ nanorod arrays on $\mathrm{Si}$ substrates [21]. When the reaction proceeds at $650{ }^{\circ} \mathrm{C}, \mathrm{TiS}_{3}$ seeds are decomposed into $\mathrm{TiS}_{2}$ particles resulting in films of $\mathrm{TiS}_{2}$. Compared with our previous experiments [19], we think that the reaction time influences the stoichiometries and morphologies of the products formed.

\subsection{UPS analysis}

Work functions of the materials were measured in ultrahigh vacuum using the inelastic secondary electron cutoff of UPS energy distribution curves [22]. Before the spectra were recorded, the surfaces of the samples were cleaned by $\mathrm{Ar}^{+}$sputtering with an applied energy of $2 \mathrm{keV}$ and a beam density of $0.5 \mu \mathrm{A} / \mathrm{mm}^{2}$ for $200 \mathrm{~s}$. After a high purity Ni plate was sputtered, its UPS spectrum on the kinetic energy scale was recorded as shown in Fig. 5(a), and

\section{(国 Springer}


the spectrometer was calibrated by the Fermi edge of Ni. The spectrum width from the Fermi edge to the sample inelastic cutoff, as determined by the centers of the slopes (Fig. 5(a)), is equal to $h v-\Phi$ (where $h v$ is the photon energy and $\Phi$ is the work function) [22]; the work function of $\mathrm{Ni}$ was confirmed as $4.01 \mathrm{eV}$, The UPS spectra of $\mathrm{TiS}_{3}$ and $\mathrm{TiS}_{1.71}$ are shown in Figs. 5(b) and 5(c), respectively. The positions of the sample inelastic cutoff for $\mathrm{TiS}_{3}$ and $\mathrm{TiS}_{1.71}$ correspond to values of the work functions of 4.60 and $4.44 \mathrm{eV}$, respectively (although the Fermi edge is not observed, the value can be taken as the same as that for $\mathrm{Ni}$, since the Fermi edge is the reference point of the energy scale in UPS and should not change from sample to sample as long as they are grounded [22]).

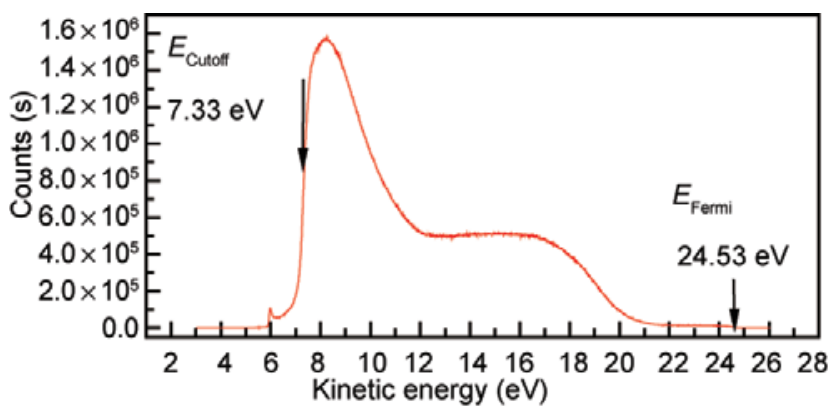

(a)

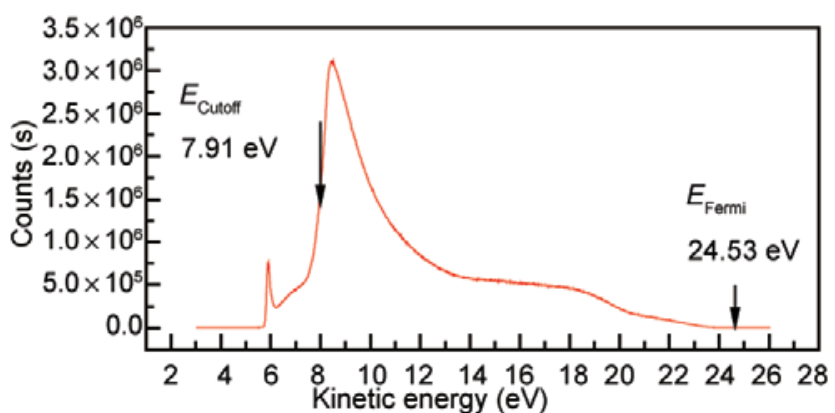

(b)

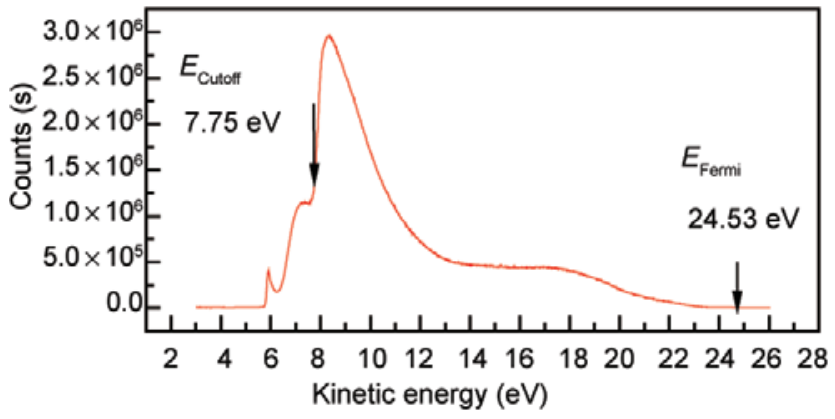

(c)

Figure 5 UPS spectra of (a) Ni plate, (b) $\mathrm{TiS}_{3}$ nanobelt film, and (c) TiS $_{171}$ nanobelt film.

\subsection{Electronic field emission}

The emission current-voltage characteristics were analyzed by using the Fowler-Nordheim $(\mathrm{F}-\mathrm{N})$ equation for the field emission: $J=\left(A E^{2} \beta^{2} / \Phi\right)$. $\exp \left[-B \Phi^{3 / 2} /(E \beta)\right]$, where $J$ is the current density $\left(\mathrm{A} / \mathrm{m}^{2}\right), E$ is the applied field, $B=6.83 \times 10^{9}\left(\mathrm{eV}^{-3 / 2} \mathrm{~V} \cdot \mathrm{m}^{-1}\right)$, $\mathrm{A}=1.56 \times 10^{-10}\left(\mathrm{AV}^{-2} \cdot \mathrm{eV}\right), \beta$ is a field enhancement factor, and $\Phi$ is the work function [23]. Figures 6 (a) and 6(b) depict the curves of the emission current density $(J)$ as a function of applied field $(E)$ of the $\mathrm{TiS}_{3}$ nanobelt films obtained at $450{ }^{\circ} \mathrm{C}$ and the $\mathrm{TiS}_{1.71}$ nanobelt films, respectively, and insets show the corresponding $\mathrm{F}-\mathrm{N}$ plots, that is, the plots of $\ln \left(J / E^{2}\right)$ versus $1 / \mathrm{E}$. The $\mathrm{F}-\mathrm{N}$ plots exhibit an approximately linear behavior in the low field region but nonlinear behavior in the high field region, which may result from space charge effects in the vacuum space [24]. Based on the $J-E$ curves, we can determine the field emission turn-on fields and threshold fields, which are defined as the macroscopic fields required to produce a current density of $10 \mu \mathrm{A} / \mathrm{cm}^{2}$ and $1 \mathrm{~mA} /$ $\mathrm{cm}^{2}$, respectively. The turn-on fields of $\mathrm{TiS}_{3}$ and $\mathrm{TiS}_{1.71}$ are 1.0 and $0.9 \mathrm{~V} / \mu \mathrm{m}$, respectively, and the threshold fields are 5.6 and $4.0 \mathrm{~V} / \mu \mathrm{m}$, respectively. Based the on work functions of $\mathrm{TiS}_{3}(4.60 \mathrm{eV})$ and $\mathrm{TiS}_{1.71}(4.44 \mathrm{eV})$ determined as above, and the slopes of the $\mathrm{F}-\mathrm{N}$ plots, field enhancement factors of the $\mathrm{TiS}_{3}$ and $\mathrm{TiS}_{1.71}$ nanobelt films are calculated as $1.63 \times 10^{4}$ and $\sim 2.14 \times 10^{4}$, respectively. Both turnon fields and threshold fields are comparable to the

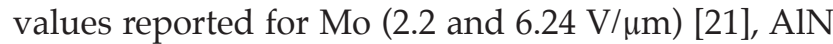
(3.8 and $7 \mathrm{~V} / \mu \mathrm{m})$ [25], and $\mathrm{ZrS}_{2}(0.95$ and $3.6 \mathrm{~V} / \mu \mathrm{m})$ nanowire arrays [26]. Therefore, both nanostructures are candidates for future field emitters. Because the $\mathrm{TiS}_{1.71}$ nanobelt films were prepared by vacuum pyrolysis of the $\mathrm{TiS}_{3}$ nanobelt films, the amounts (per $\mathrm{cm}^{2}$ ) and morphologies of the two nanostructures are very similar. Therefore, the FE performances of the materials depend strongly on their work function. It should be noted that the work function measured here is an average over the emitting material and the local work function at the tips of individual 1-D nanostructures, where most electrons are emitted, has an important effect on the FE properties [27, 28]. The maximal emission current of the $\mathrm{TiS}_{1.71}$ nanobelt 
arrays is greater than that of the $\mathrm{TiS}_{3}$ nanobelt arrays, which may be attributed to the greater stability of the $\mathrm{TiS}_{1.71}$ nanobelts. Emission stabilities of the $\mathrm{TiS}_{1.71}$ nanobelt films were tested at a constant electric field

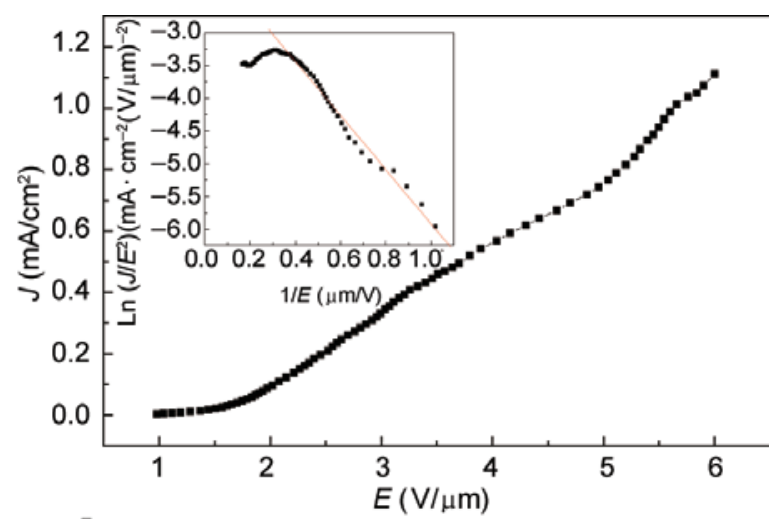

(a)

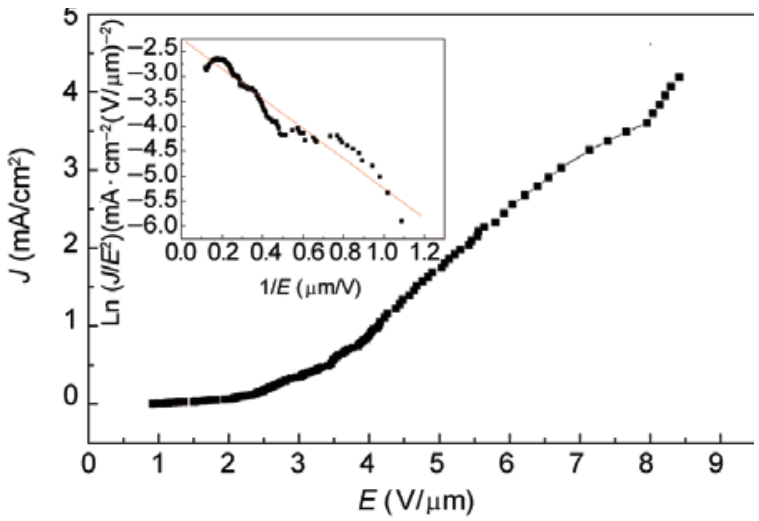

(b)

Figure 6 Current density-electric field curves for (a) $\mathrm{TiS}_{3}$ nanobelt films obtained at $450{ }^{\circ} \mathrm{C}$ and (b) $\mathrm{TiS}_{1.71}$ nanobelt films obtained by vacuum pyrolysis of the above $\mathrm{TiS}_{3}$ nanobelt films at $600{ }^{\circ} \mathrm{C}$ for $2 \mathrm{~h}$. Insets are the corresponding $\mathrm{F}-\mathrm{N}$ plots

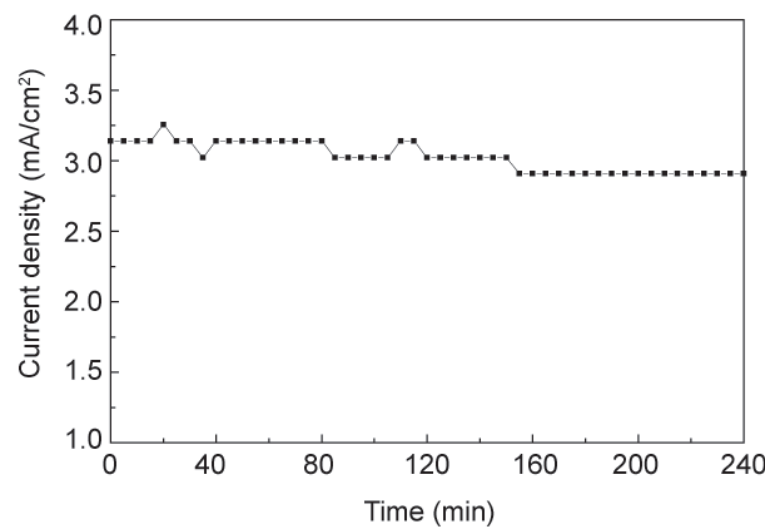

Figure 7 Emission current density vs. time curves for $\mathrm{TiS}_{171}$ nanobelt films at $7.0 \mathrm{~V} / \mu \mathrm{m}$ of $7.0 \mathrm{~V} / \mu \mathrm{m}$. As shown in Fig. 7 , the initial current and the average current densities were 3.14 and 3.03 $\mathrm{mA} / \mathrm{cm}^{2}$, respectively, and no obvious degradation of current densities was observed after $4 \mathrm{~h}$.

\section{Conclusions}

$\mathrm{TiS}_{3}$ nanobelt films have been fabricated on $\mathrm{Ti}$ substrates by a facile surface-assisted chemical-vaportransport approach. The morphologies and structures strongly depend on the reaction conditions including quantities of reagents, reaction temperature, and reaction time. $\mathrm{TiS}_{3}$ nanobelt films can be decomposed to give $\mathrm{TiS}_{1.71}$ nanobelt films by vacuum pyrolysis. Both films possess low turn-on fields and high field enhancement factors. These properties could make the nanobelt film ensembles highly valuable for use in novel FE nanodevices.

\section{Acknowledgements}

We acknowledge the financial support from the National Natural Science Foundation of China (No. 20671050), and National Basic Research Program of China (973 Program, No. 2007CB936302).

\section{References}

[1] Bawendi, M. G.; Steigerwald, M. L.; Brus, L. E. The quantum-mechanics of larger semiconductor clusters (quantum dots). Annu. Rev. Phys. Chem. 1990, 41, 477496.

[2] Alivisatos, A. P. Semiconductor clusters, nanocrystals, and quantum dots. Science 1996, 271, 933-937.

[3] Weller, H. Colloidal semiconductor Q-particlesChemistry in the transition region between solid-state and molecules. Angew. Chem. Int. Ed. 1993, 32, 41-53.

[4] Xia, Y.; Yang, P.; Sun, Y.; Wu, Y.; Mayers, B.; Gates, B.; Yin, Y.; Kim, F.; Yan, H. One-dimensional nanostructures: Synthesis, characterization, and applications. Adv. Mater. 2003, 15, 353-389.

[5] Kovtyukhova, N. I.; Mallouk, T. E. Nanowires as building blocks for self-assembling logic and memory circuits. Chem. Eur. J. 2002, 8, 4355-4363.

[6] Bavykin, D. V.; Friedrich, J. M.; Walsh, F. C. Protonated titanates and $\mathrm{TiO}_{2}$ nanostructured materials: Synthesis, 
properties, and applications. Adv. Mater. 2006, 18, 2807 $-2824$

[7] Wu, X. C.; Tao, Y. R.; Hu, Y. M.; Song, Y.; Hu, Z.; Zhu, J. J.; Dong, L. Tantalum disulfide nanobelts: Preparation, superconductivity and field emission. Nanotechnology 2006, 17, 201-205.

[8] Fang, X.; Bando, Y.; Ye, C.; Golberg, D. Crystal orientation-ordered ZnS nanobelt quasi-arrays and their enhanced field-emission. Chem. Commun. 2007, 30483050.

[9] Yoon, H.; Seo, K.; Moon, H.; Varadwaj, K. S. K.; In, J.; Kim, B. Aluminum foil mediated noncatalytic growth of $\mathrm{ZnO}$ nanowire arrays on an indium tin oxide substrate. J. Phys. Chem. C 2008, 112, 9181-9185.

[10] Li, L.; Fang, X.; Chew, H. G.; Zheng, F.; Liew, T. H.; Xu, X.; Zhang, Y.; Pan, S.; Li, G.; Zhang, L. Crystallinitycontrolled germanium nanowire arrays: Potential field emitters. Adv. Funct. Mater. 2008, 18, 1080-1088.

[11] Ait-Ouali, A.; Jandl, S. Photoluminescence study of the one-dimensional material $\mathrm{ZrS}_{3}$ and its solid solution $\mathrm{Zr}_{1-x} \mathrm{Hf}_{x} \mathrm{~S}_{3}$. Phys. Rev. B 1996, 53, 9852-9858.

[12] Shepherd, F. R.; Williams, P. M. Photoemission studies of band structures of transition-metal dichalcogenides. 1. Group-IVA and Group-IVB. J. Phys. C: Solid State Phys. 1974, 7, 4416-4426.

[13] Chen, C. H.; Fabian, W.; Brown, F. C.; Woo, K. C.; Davies, B.; De Long, B.; Thompson, A. H. Angle-resolved photoemission-studies of the band-structure of $\mathrm{TiSe}_{2}$ and $\mathrm{TiS}_{2}$. Phys. Rev. B. 1980, 21, 615-624.

[14] Chang, H. S. W.; Schleich, D. M. TiS 2 and TiS 3 thin-films prepared by MocVD. J. Solid State Chem. 1992, 100, 6270.

[15] Ma, J. J.; Liu, X.Y.; Cao, X. J.; Feng, S. H.; Fleet, M. E. Bundle of nanobelts up to $4 \mathrm{~cm}$ in length: One-step synthesis and preparation of titanium trisulfide $\left(\mathrm{TiS}_{3}\right)$ nanomaterials. Eur. J. Inorg. Chem. 2006, 519-522.

[16] Nath, M.; Rao, C. N. R. Nanotubes of group 4 metal disulfides. Angew. Chem. 2002, 41, 3451-3454.

[17] Chen, J.; Tao, Z. L.; Li, S. L. Lithium intercalation in openended $\mathrm{TiS}_{2}$ nanotubes. Angew. Chem. Int. Ed. 2003, 42, 2147-2151.
[18] Zhang, Y.; Li, Z. K.; Jia, H. B.; Luo, X. H.; Xu, J.; Zhang, X. H.; Yu, D. P. TiS 2 whisker growth by a simple vapordeposition meth. J. Cryst. Growth 2006, 293, 124-127.

[19]Tao, Y. R.; Wu, X. C.; Zhang, Y. L.; Dong, L.; Zhu, J. J.; $\mathrm{Hu}, Z$. Surface-assisted synthesis of microscale hexagonal plates and flower-like patterns of single-crystalline titanium disulfide and their field-emission properties. Cryst. Growth Des. 2008, 8, 2990-2994.

[20] Jennings, H. M. On reactions between silicon and nitrogen. 1. Mechanisms. J. Mater. Sci. 1983, 18, $951-$ 967.

[21] Zhou, J.; Xu, N. S.; Deng, S. Z.; Chen, J.; She, J. C.; Wang, Z. L. Large-area nanowire arrays of molybdenum and molybdenum oxides: Synthesis and field emission properties. Adv. Mater. 2003, 15, 1835-1840.

[22] Park, Y.; Choong, V.; Gao, Y.; Hsieh, B. R.; Tang, C. W. Work function of indium tin oxide transparent conductor measured by photoelectron spectroscopy. Appl. Phys. Lett. 1996, 68, 2699-2701.

[23] Gadzuk, J. W.; Plummer, E. W. Field-emission energydistribution (FEED). Rev. Mod. Phys. 1973, 45, 487-548.

[24] Xu, N. S.; Chen, Y.; Deng, S. Z.; Chen, J.; Ma, X. C.; Wang, E. G. Vacuum gap dependence of field electron emission properties of large area multi-walled carbon nanotube films. J. Phys. D: Appl. Phys. 2001, 34,15971601.

[25] He, J. H.; Yang, R.; Chueh, Y. L.; Chou, L. J.; Chen, L. J.; Wang, Z. L. Aligned AIN nanorods with multitipped surfaces-Growth, field-emission, and cathodoluminescence properties. Adv. Mater. 2006, 18, 650-654.

[26] Zhang, Y. L.; Wu, X. C.; Tao, Y. R.; Mao, C. J.; Zhu, J. J. Fabrication and field-emission performance of zirconium disulfide nanobelt arrays. Chem. Comm. 2008, 26832685.

[27] Bai, X.; Wang, E. G.; Gao, P.; Wang, Z. L. Measuring the work function at a nanobelt tip and at a nanoparticle surface. Nano Lett. 2003, 3, 1147-1150.

[28] Xu, Z.; Bai, X. D.; Wang, E. G.; Wang, Z. L. Field emission of individual carbon nanotube with in situ tip image and real work function. Appl. Phys. Lett. 2005, 87, 163106. 